\title{
Pre-transplant Quantitative Determination of NPM1 Mutation Significantly Predicts Outcome of AIlogeneic Hematopoietic Stem Cell Transplantation in Patients with Normal Karyotype AML in Complete Remission
}

\author{
MICHAL KARAS ${ }^{1}$, KATERINA STEINEROVA ${ }^{1}$, DANIEL LYSAK ${ }^{1}$, MARCELA HRABETOVA ${ }^{1}$, \\ ALEXANDRA JUNGOVA $^{1}$, JIRI SRAMEK ${ }^{1}$, PAVEL JINDRA ${ }^{1}$, JIRI POLIVKA ${ }^{2,3}$ and LUBOS HOLUBEC ${ }^{2}$ \\ ${ }^{1}$ Department of Haematology and Oncology, Faculty Hospital Plzen, Plzen, Czech Republic; \\ ${ }^{2}$ Biomedical Center, and ${ }^{3}$ Department of Histology and Embryology, \\ Faculty of Medicine in Plzen, Charles University Prague, Plzen, Czech Republic
}

\begin{abstract}
Background/Aim: Minimal residual disease $(M R D)$ in patients with acute myeloid leukemia (AML) before allogeneic hematopoietic stem cell transplantation (alloHSCT) can influence the results of therapy. With the aim of evaluating the potential role of pre-transplant MRD, we studied the impact of pre-transplant MRD level on the outcome of alloHSCT in patients with AML in complete remission (CR). Patients and Methods: From 2/2005 to 9/2014, 60 patients with a median age of 54 years (range $=30-66$ years) with normal karyotype-AML harboring nucleophosmin 1 (NPM1) mutation [53\% Fms-related tyrosine kinase receptor 3 internal tandem duplication (FLT3/ITD)-positive] in first $(n=45)$ or second $(n=15) C R$ underwent myeloablative $(n=16)$ or reduced-intensity $(n=44)$ alloHSCT (27\% related, $73 \%$ unrelated). The MRD level was determined from bone marrow samples using real-time polymerase chain reaction for detection of NPMI mutations before starting the conditioning regimen. Results: The estimated probabilities of 3-year relapse, event-free survival (EFS) and overall survival (OS) for the whole cohort were $28 \%, 54 \%$, and 59\%, respectively. Statistical analysis showed that only age over 63 years and high MRD level affected alloHSCT outcome. Pre-transplant MRD level of 10 mutant copies of NPM1 per 10,000 Abelson murine leukemia
\end{abstract}

Correspondence to: Michal Karas, MD, Department of Haematology and Oncology, Faculty Hospital Plzen, alej Svobody 80, 30460 Pilsen, Czech Republic. Tel: +420 377104627, Fax: +420 377104623, e-mail: karas@fnplzen.cz

Key Words: Acute myeloid leukemia, minimal residual disease, allogeneic hematopoietic stem cell transplantation, nucleophosmin 1 mutation. viral oncogene homolog $1(A B L)$ copies had the strongest statistical significance, and detection of higher MRD level (>10 NPM1-mutant copies) before alloHSCT was associated with increased overall mortality (hazard ratio $=3.71 ; 95 \%$ confidence interval $=1.55-9.06 ; p=0.004)$. The estimated probabilities of 3-year relapse, EFS, and OS were 6\%, 72\%, and $75 \%$ for patients with a low level of MRD and $48 \%$, $35 \%$, and $40 \%$ for patients with a higher level. Conclusion: Our data showed that the pre-transplant level of MRD in patients with normal karyotype AML harboring NPMI mutation in CR provides important prognostic information, which as an independent prognostic factor predicts transplant results.

Acute myeloid leukemia (AML) is currently curatively treated using an intensive induction chemotherapy treatment, which generally achieves complete remission (CR) in about $60-80 \%$ of cases. However, without further consolidation treatment, relapse would occur in most patients. Consolidation treatment options essentially consist of either further chemotherapy or allogenic hematopoietic stem cell transplantation (alloHSCT), and a range of prognostic factors are important for the choice of consolidation therapy (1-5). While the strategies and methods of curative treatment of AML have undergone no major changes over the last 20 years, the past decade has seen an improvement in treatment results due to more detailed insight into AML biology and improvements in supportive treatment, which make it possible to manage once-fatal complications of intensive chemotherapy or alloHSCT. AlloHSCT is currently the most effective treatment for AML. Mainly due to improvements in supportive treatment and transplant procedures, mortality from transplant (TRM) has fallen significantly, and a wider spectrum of patients can now undergo alloHSCT $(6,7)$. At 
the same time, a number of studies have investigated the role of alloHSCT in AML treatment (8-12). With TRM decreasing, AML relapse after alloHSCT remains the principal limitation to transplant outcomes, especially because the prognosis of AML relapse after alloHSCT is highly unfavorable (13). For this reason, efforts are underway to identify additional prognostic factors that may help determine which patients are at increased risk of AML relapse after alloHSCT.

In recent years, the importance of the detection of minimal residual disease (MRD) for the prediction of AML treatment outcomes has been rising. With regard to chemotherapy of AML, the published data seems to indicate that treatment response evaluation based on MRD detection is among the independent prognostic factors relevant to risk of relapse and therefore to AML treatment results (14-26). In alloHSCT, where the efficacy of treatment is significantly influenced by the graft-versus-host disease (GVHD) effect and which has proven effective even in the case of chemoresistant AML, with a reported long-term survival of $20-30 \%$, it is important to ask whether a finding of MRD before alloHSCT has an impact on transplant outcome $(27,28)$. Moreover, most patients with AML undergo alloHSCT in CR, i.e. at a time when any potential residual disease is generally lower than in resistant AML. Considering the importance of the GvL effect, it is a key question whether determining MRD in AML in CR before alloHSCT can offer prognostic information about the treatment outcome, as it does with intensive chemotherapy. The importance of determining MRD before alloHSCT is thus the subject of intensive research; findings published so far, which mostly used multiparametric flow cytometry to detect MRD, indicate that determining MRD before alloHSCT may carry prognostic information about the transplant outcome. However, the existing research is frequently limited by a small number of studied patients, inclusion of heterogeneous AML types, different diagnostic methods for MRD determination, as well as the fact that support for MRD importance is not universal among these studies (29-35).

With the aim of evaluating the importance of determining the level of MRD levels before alloHSCT in patients with AML in CR, we analyzed alloHSCT outcomes in patients in first or second CR of normal karyotype AML (NK-AML) with NPM1 gene mutation. AML with normal karyotype represents the largest group of patients with AML and the most common molecular lesion in this group is a mutation in the gene encoding nucleophosmin (NPM1). NPM1 mutation was also previously found to be a suitable and stable marker of MRD in a number of published studies (1619). We used the relative expression of the mutated NPMI gene, evaluated using real-time polymerase chain reaction (RT-PCR), as a marker for MRD monitoring immediately prior to the start of the conditioning regimen.

\section{Patients and Methods}

Study group. Our study group was made up of all patients aged 18 and above diagnosed with NK-AML with an NPM1 gene mutation (types A, B, and D) at the Department of Hematology and Oncology of the University Hospital in Pilsen and who underwent alloHSCT in first or second CR between January 2005 and September 2014. AML was diagnosed according to the World Health Organization (WHO) classification (36).

Cytogenetic examination by G-banding was performed on all AML samples at the time of diagnosis. NPM1 gene mutation presence and type were determined by DNA sequencing and quantitative examination of initial relative expression of mutated NPM1 was also performed. As part of the molecular genetic marker assay, presence of Fms-related tyrosine kinase receptor 3 internal tandem duplication (FLT3/ITD) was also determined for all patients at the time of diagnosis. Complete remission of AML was evaluated according to standard recommendations (37).

Human leukocyte antigen (HLA) typing of donors and recipients was performed according the European Federation for Immunogenetics/European Society for Blood and Marrow Transplantation (EFI/EBMT) recommendations (accessible at www.efiweb.eu/efi-committees/standards-committee.htlm) in an EFI-accredited laboratory. Acute and chronic GVHD was diagnosed according to published criteria $(38,39)$.

All patients were evaluated post-transplant for overall survival (OS), event-free survival (EFS), TRM, and incidence of relapse. All patients were treated according to protocols approved by the Quality Control Boards of a Joint Accreditation Committee-ISCT and EBMT accredited facility and all patients provided consent for monitoring and data processing in accordance with the Declaration of Helsinki.

Detection of MRD. Bone marrow sample collection for MRD detection was performed no later than 1 week before the start of the pre-transplant conditioning regimen. RNA was isolated from bone marrow samples using the commercial QIAamp RNA Blood Mini Kit (Qiagen, Hilden, Germany). cDNA was synthesized from 500 ng of RNA using SuperScript III First Strand Synthesis SuperMix commercial kit (Invitrogen, Carlsbad, CA, USA).

Quantitative real-time PCR was performed on the samples using the NPM1Quant kit (Ipsogen SA, Marseille, France). The calibration curves for the quantitative assessment of the number of copies of the mutated NPM1 gene and the control gene $A B L$ were determined based on the standards supplied with the kit for all analyses. All samples were analyzed in duplicate, using the average of the two analyses in further calculations. If the threshold cycle (Ct) discrepancy between the two samples exceeded 0.6 cycles, the analysis was repeated. The minimum required expression for the $A B L$ gene control was set at 3,000 copies. The results of the expression analysis of the mutated NPM1 gene are given as the number of copies of mutated NPM1 per 10,000 copies of $A B L$. Amplification and data analysis were performed on Light Cycler version 1.5 or version 2.0 devices (Roche Applied Science, Mannheim, Germany). The assays were performed at the accredited Molecular Genetics Laboratory of Department of Hematology and Oncology, Faculty Hospital, Plzen, Czech Repblic and the method of relative quantification of mutated $N P M 1$ was regularly verified, validated and monitored as part of external inter-laboratory quality control processes. 
Table I. Characteristics of the study group of patients with acute myeloid leukemia (AML).

\begin{tabular}{lc}
\hline Characteristic & Value \\
\hline Median of age (range), years & $54(30-66)$ \\
Gender, n (\%) & $32(53 \%)$ \\
$\quad$ Male & $28(47 \%)$ \\
Female & \\
AML status, n (\%) & $45(75 \%)$ \\
CR1 & $15(25 \%)$ \\
CR2 & $32(53 \%)$ \\
FLT3/ITD positivity, n (\%) & \\
Conditioning protocol, n (\%) & $16(27 \%)$ \\
Myeloablative & $44(73 \%)$ \\
Reduced-intensity & \\
Type of donor, n (\%) & $16(27 \%)$ \\
Related & $44(73 \%)$ \\
Unrelated & $12(20 \%)$ \\
Gender recipient/donor, n (\%) & $48(80 \%)$ \\
Male/female & \\
Other & $6(10 \%)$ \\
CMV status recipient/donor,n $(\%)$ & $54(90 \%)$ \\
Negative/negative & \\
Other & $12(20 \%)$ \\
Source of stem cells, n (\%) & $48(80 \%)$ \\
Bone marrow & $60(100 \%)$ \\
PBSC & $0(0 \%)$ \\
WHO status, n (\%) & \\
0-1 & \\
$\geq 2$ & \\
\end{tabular}

CR: First complete remission; CR2: second complete remission; FLT3/ITD: Fms-related tyrosine kinase receptor 3 internal tandem duplication; CMV: cytomegalovirus; PBSC: peripheral blood stem cells.

Statistical analysis. Patient characteristics were summarized using frequency tables and standard descriptive statistics, Pearson chisquare test, Fisher's exact test, and $t$-test.

OS was calculated from the date of alloHSCT until death from any cause, and surviving patients were censored at the last followup. The EFS was calculated from the date of alloHSCT until death or relapse, and patients who were alive and disease-free were censored at the last follow-up. Probabilities of OS and EFS were estimated using the Kaplan-Meier method. TRM was defined as death due to any cause unrelated to disease. Probabilities of TRM and relapse were summarized using cumulative incidence estimates. Cumulative incidence of TRM and relapse were adjusting for competing risk. TRM was a competing risk for relapse, while relapse was a competing risk for TRM. Univariate analyses to evaluate differences in survival between groups of patients were performed using the log-rank and Wilcoxon tests. The Cox proportional hazards model was considered for the survival modeling to specify the role of individual prognostic factors in assessing the OS and EFS. The multivariable Cox proportional hazards model (stepwise regression) was used for identification of the significant prognostic factors in OS and EFS. The level of statistical significance of $\alpha=0.05$ was used in all analyses. All
Table II. Transplant results of the entire study group.

\begin{tabular}{lc}
\hline Characteristic & $\mathrm{n}(\%)$ \\
\hline Acute GVHD & $36(60 \%)$ \\
Acute GVHD III-IV & $8(13 \%)$ \\
Chronic GVHD & $24(40 \%)$ \\
Mild chronic GVHD & $12(20 \%)$ \\
Moderate chronic GVHD & $8(13 \%)$ \\
Severe chronic GVHD & $4(7 \%)$ \\
3-Year cumulative relapse & $28 \%$ \\
3-Year cumulative TRM, $\%$ & $21 \%$ \\
3-Year EFS & $54 \%$ \\
3-Year OS & $59 \%$ \\
\hline
\end{tabular}

GVHD: Graft-versus-host disease; TRM: transplant-related mortality; EFS: event-free survival; OS: overall survival.

computations were performed using SAS software (SAS Institute Inc., Cary, NC, USA) and STATISTICA software (StatSoft, Inc., Tulsa, OK, USA).

\section{Results}

Patient characteristics. The group of patients consisted of 60 individuals ( 32 women, 28 men), with a median age of 54 years (range: 30-66) with $N K-A M L$ and NPM1 mutation. FLT3/ITD was found in 32 patients $(53 \%)$ at the time of diagnosis. All patients underwent alloHSCT, most $(73 \%)$ from an unrelated donor. More patients underwent alloHSCT after reduced-intensity conditioning (RIC) $(73 \%)$ than after myeloablative conditioning (MAC). The RIC consisted of a combination of fludarabine $\left(30 \mathrm{mg} / \mathrm{m}^{2} /\right.$ day for 4 days $)$ and melphalan $\left(140 \mathrm{mg} / \mathrm{m}^{2} /\right.$ day for 1 day); the MAC consisted of a combination of busulfan $(3.2 \mathrm{mg} / \mathrm{kg} /$ day $i . v$. for 4 days $)$ and cyclophosphamide (60 mg/kg/day for 2 days). In unrelated alloHSCT, ATG Fresenius $\mathrm{S}$ (15 mg/kg dose) was used as part of the conditioning regimen. The source of the hematopoietic stem cells was mainly peripheral blood stem cells $(80 \%)$.

At the time of transplant, the WHO performance status of patients was between 0 and 1 . The median follow-up of surviving patients was 55 months (range=6-101 months). Cyclosporine A and methotrexate were administered to all patients as GVHD prophylaxis. Patient characteristics are summarized in Table I.

Transplant outcomes of the entire study group. All patients underwent transplant and were in CR at day 30 posttransplant. Although many patients developed acute GVHD (60\%), only eight developed acute GVHD grade III-IV.

With a median follow-up of 55 months (range=6-101 months), 36 patients $(60 \%)$ remained alive. Out of the entire 
Table III. Univariate analysis of factor affecting event-free survival (EFS) and overall survival (OS).

\begin{tabular}{|c|c|c|c|c|c|c|}
\hline \multirow[b]{2}{*}{ Variable } & \multicolumn{3}{|c|}{ EFS } & \multicolumn{3}{|c|}{ OS } \\
\hline & HR & $95 \% \mathrm{CI}$ & $p$-Value & HR & $95 \% \mathrm{CI}$ & $p$-Value \\
\hline Age $>63$ years & 3.40 & $1.24-9.62$ & 0.0341 & 5.40 & $1.82-16.02$ & 0.0071 \\
\hline High $v s$. low MRD* & 3.69 & $1.60-8.51$ & 0.0021 & 3.50 & $1.40-8.47$ & 0.0034 \\
\hline FLT3/ITD positivity & 1.29 & $0.60-2.78$ & 0.51 & 1.05 & $0.47-2.34$ & 0.90 \\
\hline CR2 vs. CR1 & 1.72 & $0.77-3.87$ & 0.19 & 1.92 & $0.82-4.49$ & 0.13 \\
\hline RIT vs. MAT & 1.14 & $0.48-2.71$ & 0.76 & 1.71 & $0.63-4.58$ & 0.29 \\
\hline Unrelated $v s$. related donor & 0.98 & $0.42-2.32$ & 0.97 & 1.22 & $0.45-2.83$ & 0.81 \\
\hline $\mathrm{BM} v s$. PBSCs & 1.18 & $0.50-2.81$ & 0.70 & 1.09 & $0.43-2.74$ & 0.86 \\
\hline Recipent M/donor F vs. other & 1.00 & $0.38-2.66$ & 0.99 & 1.77 & $0.53-5.95$ & 0.35 \\
\hline CMV donor/recipient positive $v s$. other & 2.16 & $0.97-4.83$ & 0.06 & 1.75 & $0.76-3.99$ & 0.18 \\
\hline
\end{tabular}

HR: Hazard ratio; CI: confidence interval; CR1: first complete remission; CR2: second complete remission; RIT: reduced-intesity transplantation; MAT: myeloablative transplantation; BM: bone marrow; PBSC: peripheral blood stem cells; M: male; F: female. *High level of minimal residual disease (MRD): nucleophosmin $1(N P M 1)>10$ copies/10,000 copies Abelson murine leukemia viral oncogene homolog $1(A B L)$.

Table IV. Multivariate analysis of factors affecting event-free survival (EFS) and overall survival (OS).

\begin{tabular}{|c|c|c|c|c|c|c|}
\hline \multirow[b]{2}{*}{ Variable } & \multicolumn{3}{|c|}{ EFS } & \multicolumn{3}{|c|}{ OS } \\
\hline & HR & $95 \% \mathrm{CI}$ & $p$-Value & HR & $95 \% \mathrm{CI}$ & $p$-Value \\
\hline Age $>63$ years & 3.40 & $1.24-9.62$ & 0.0341 & 6.23 & $1.99-19.48$ & 0.0017 \\
\hline High vs. low MRD* & 3.69 & $1.60-8.51$ & 0.0021 & 3.71 & $1.52-9.06$ & 0.0040 \\
\hline
\end{tabular}

*High level of minimal residual disease (MRD): nucleophosmin $1(N P M 1)>10$ copies/10,000 copies Abelson murine leukemia viral oncogene homolog $1(A B L)$.

group, 16 patients experienced relapsed. The median time from transplant to relapse was 4 months (range=3-13 months). Thirteen patients died as a result of relapse, two patients achieved a subsequent CR lasting 51 and 61 months, respectively, and one patient was alive in relapse.

Eleven patients (18\%) had died due to TRM. The most common cause of death (64\% of TRM cases) was infectious complications related to acute or chronic GVHD. One-year TRM was $13 \%$. Estimated 3-year EFS, OS, cumulative incidence of TRM, and cumulative incidence of relapse were, for the whole group, 54\%, 59\%, 18\%, and $28 \%$, respectively. Transplant outcomes for the entire study group are summarized in Table II and Figure 1.

Importance of pre-transplant prognostic markers for transplant outcome. In univariate analysis of the listed pretransplant prognostic factors, only age over 63 years and the pre-transplant MRD level (most significant for those above 10 mutated NPM1 copies per 10,000 ABL copies) had a statistically significant negative impact on EFS and OS. A negative trend in EFS and OS was found for alloHSCT having been performed in the second (as opposed to first) $\mathrm{CR}$ and for positive serological cytomegalovirus (CMV) status of donor and recipient, but these trends were not statistically significant. Univariate analysis of factors affecting EFS and OS is summarized in Table III.

Multivariate analysis of the listed pre-transplant factors confirmed a statistically significant negative prognostic impact on EFS and OS for age over 63 years and the level of pre-transplant MRD (most significant for levels above 10 mutated NPMI copies per 10,000 ABL copies). Multivariate analysis results are summarized in Table IV.

Importance of pre-transplant residual disease level for transplant outcome. As the relative expression of mutated NPM1 was known at the time of $A M L$ diagnosis [median=38,245 $($ range $=14,350-144,707)$ mutated NPM1 copies per 10,000 $A B L$ copies], it was possible to evaluate pre-transplant MRD with two different methods: (i) as solely the pre-transplant relative expression of mutated NPM1, and (ii) as the decrease in relative expression of mutated NPMI between initial AML diagnosis and immediately before the 

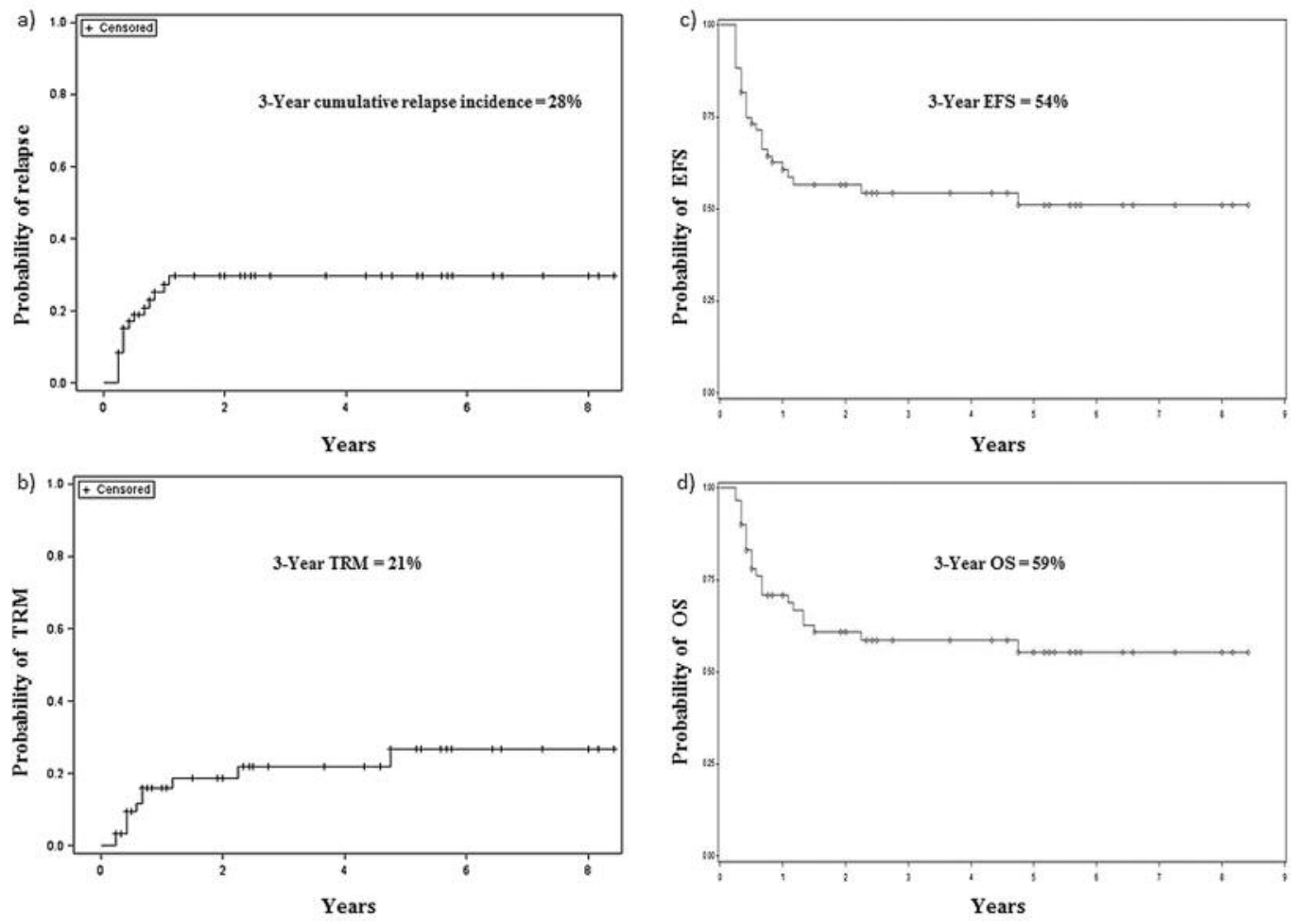

Figure 1. Probability of relapse (a), transplant-related mortality (b), event-free survival (EFS) $(c)$ and overall survival $(O S)(d)$ for the entire group of patients.

transplant procedure. Higher levels of statistical significance were achieved using the first method, i.e. measuring only the pre-transplant level of relative expression of mutated NPM1. We set the cut-off point at 10 mutated NPMI copies per $10,000 \mathrm{ABL}$ copies, as this division of the patient group produced the most statistically significant difference in EFS and OS, although statistically significant differences were also found for several other cut-off values (see Figure 2).

The division of the patient cohort by pre-transplant MRD level (more or less than 10 mutated NPMI copies per 10,000 $A B L$ copies) reveals a marked difference in the results of the alloHSCT. Considering the entire patient group, 16 patients $(28 \%)$ experienced relapse. However, in the low-MRD group there were only two patients with relapse $(6 \%$ of the lowMRD group), while in the high-MRD group there were 14 (48\% of the high-MRD group). A total of 11 patients $(18 \%)$ died due to TRM, five $(17 \%)$ in the high-MRD group and six $(19 \%)$ in the low-MRD group. Estimated 3-year EFS and OS for the entire study group were $54 \%$ and $59 \%$, respectively. Risk of relapse or death was 3.69 times higher in the high-MRD group than in the low-MRD group [hazard ratio $(\mathrm{HR})=3.69 ; 95 \%$ confidence interval $(\mathrm{CI})=1.60-8.51$, $p=0.0021$ ). Estimated 3 -year EFS was $35 \%$ in the high-MRD
Table V. Outcome probalities stratified by minimal residual disease (MRD) status whereby a high level of MRD was defined as nucleophosmin 1 (NPM1) >10 copies/10,000 copies Abelson murine leukemia viral oncogene homolog $1(A B L)$.

\begin{tabular}{lcc}
\hline 3-Year endpoint & Low MRD & High MRD \\
\hline CIR & $6 \%$ & $48 \%$ \\
EFS & $72 \%$ & $35 \%$ \\
OS & $75 \%$ & $40 \%$ \\
\hline
\end{tabular}

CIR: Cumulative incidence of relapse; EFS: event-free survival; OS: overall survival.

group - significantly lower than the $72 \%$ found in the lowMRD group $(p=0.0021)$. This is presented in Figure $3 \mathrm{a}$.

Risk of death was 3.71-times higher in the high-MRD group than in the low-MRD group $(\mathrm{HR}=3.71$; $95 \% \mathrm{CI}=1.52$ $9.06, p=0.0040)$. The estimated 3 -year OS rate was $40 \%$ in the high-MRD group - significantly lower than the $75 \%$ found in the low-MRD group $(p=0.004)$. This may be seen in Figure $3 b$. 

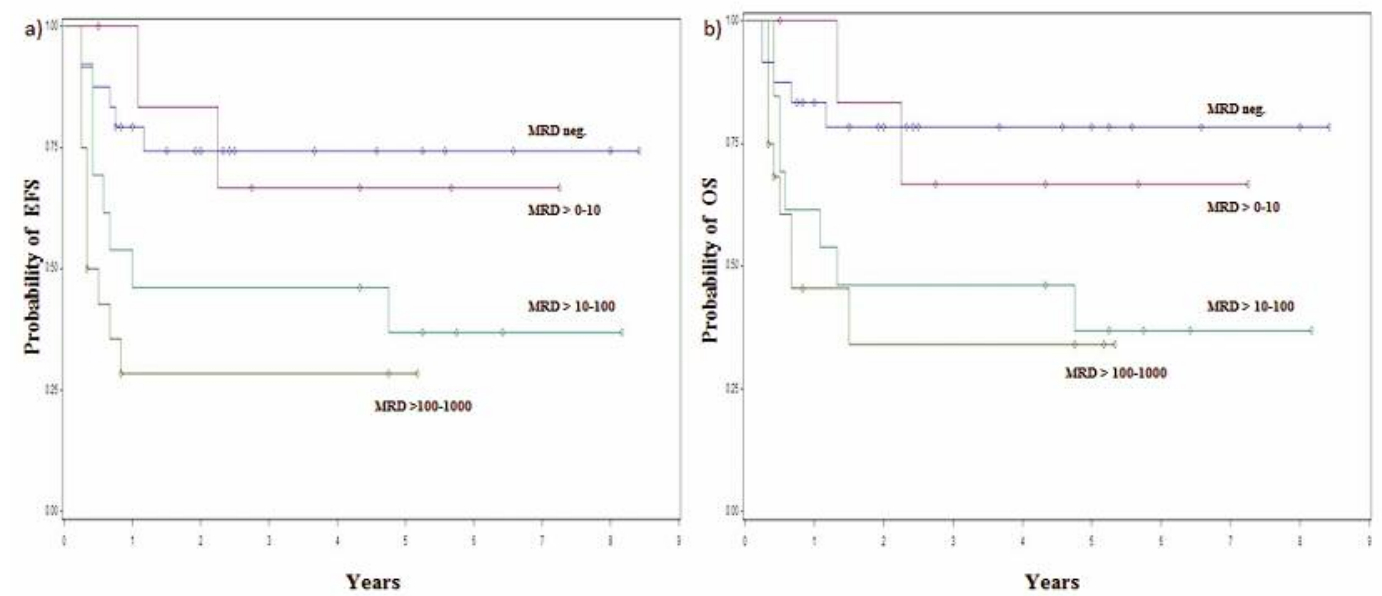

Figure 2. Probability of event-free (EFS) (a) and overall (OS) (b) survival for transplanted patients stratified by pre-transplant minimal residual disease (MRD) level [mutated nucleophosmin 1 (NPM1) copies/10,000 copies Abelson murine leukemia viral oncogene homolog 1 (ABL)].

The transplant outcomes for the patients according to pretransplant MRD level are summarized in Table V.

\section{Discussion}

We investigated the importance of pre-transplant MRD level for alloHSCT outcome in patients with NK-AML with a mutation of the NPM1 gene in first or second CR of AML. While our sample size is somewhat small, it has the virtue of being homogeneous in both diagnosis and treatment. We determined MRD according to the relative expression of mutated NPMI, evaluated using standardized RT-PCR. NPM1 mutation was previously found to be a suitable and stable marker of MRD in a number of published studies (1619, 40-42). Our sample is among the largest of studies of patients with AML examining the impact of pre-transplant MRD quantified by the expression of mutated NPM1 on transplant outcome. Thanks to a distinct molecular genetic marker, the use of RT-PCR eliminates certain limitations of multiparametric flow cytometry - in particular, its lower sensitivity and the risk of antigenic shifts in the leukemia cells $(33,43-45)$. MRD was determined immediately (less than 1 week) prior to the start of conditioning regimen. This approach reduces the risk of error in MRD measurement arising from potentially fast changes in MRD in patients with AML $(46,47)$. Other published studies either do not disclose the time interval between MRD assessment and the transplant procedure, or this interval was longer than in our study $(34,48)$.

The results of our analysis show that in our sample population, the pre-transplant MRD level in patients with NK-AML and NPMI gene mutation in CR was an independent prognostic factor for alloHSCT outcome. In our study group, determining the pre-alloHSCT relative expression of mutated $N P M 1$ proved to be a superior method of predicting alloHSCT outcome compared to the evaluation of the decrease of mutated NPMI expression between diagnosis and the transplant procedure. We assume this is due to a large range of expression levels of mutated NPMI in the AML diagnostic samples. In our study group, these results were statistically significant for several levels of pretransplant mutated NPM1 expression (negative $v s$. positive; more $v s$. less than 1 ; more $v s$. less than 10; more $v s$. less than 100 mutated NPMI copies per 10,000 ABL copies), which suggests that alloHSCT outcomes (EFS, OS) deteriorate with increasing pre-transplant MRD. This finding is not completely in line with some prior published studies, where a difference in alloHSCT outcomes had been documented only between MRD-positive and MRD-negative patients, and the impact on transplant outcome of different levels of positivity among MRD-positive patients was not further documented $(29,31)$. This might be explained by the fact that these studies used a less sensitive method of MRD detection (multiparametric flow cytometry), as well as by their lower number of enrolled MRD-positive patients which might have caused further sample divisions to fall short of statistical significance.

In our study, we chose a cut-off point of 10 mutated NPM1 copies per 10,000 ABL copies (0.1\% mutated NPM1 to ABL ratio); this cut-off value divided the entire patient cohort into two groups between which the statistical significance of the difference in EFS and OS was highest, in univariate as well as multivariate analysis. Patients with an NPMI mutation in CR and higher pre-transplant MRD level (>10 mutated NPM1 copies per 10,000 ABL copies) exhibited higher incidence of relapse and lower EFS and 

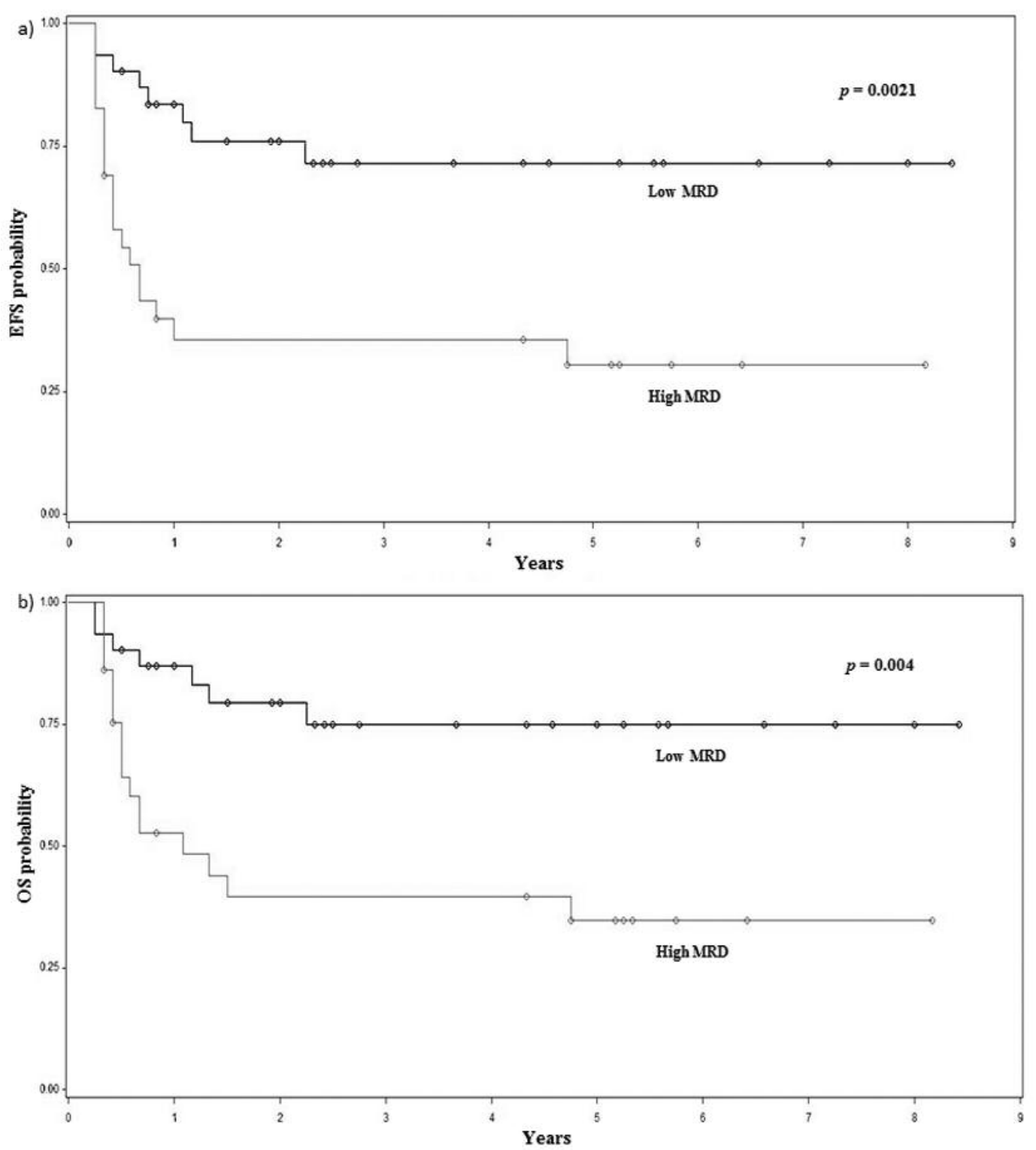

Figure 3. Probability of event-free (EFS) (a) and overall $(O S)(b)$ survival for patients with acute myeloid leukemia $(A M L)$ with negative/low level vs. high level pre-transplant minimal residual disease (MRD) status [defined by cut-off of 10 mutated nucleophosmin 1 (NPM1) copies/10,000 copies Abelson murine leukemia viral oncogene homolog $1(A B L)]$.

overall survival, while TRM was not significantly different between the two groups. Our results thus provide further support for the importance of MRD determination in alloHSCT prognosis among patients with AML, in line with the majority of previously published research (29-34, 48, 49).

An interesting finding is that FLT3/ITD positivity had no adverse effect on the transplant outcome in our group of patients with NK-AML with an NPMI mutation in CR. In other published research, diagnostic FLT3/ITD positivity had a negative impact on the prognosis of such patients $(19,46$, $50,51)$. From our results it would seem that as long as the MRD level is taken into account, diagnostic FLT3/ITD positivity or negativity among patients with AML harboring NPM1 mutations in $\mathrm{CR}$ has only minimal impact on alloHSCT outcome. Certain other researchers' results also support this conclusion (42). The status of CR of AML also had no impact on transplant outcomes in our population when pre-transplant MRD levels were taken into account, outcomes were not significantly different between patients 
in first and second CR. Similar results are also reported by other researchers who took pre-transplant MRD levels into account for transplant outcome evaluation (29, 31, 33). However, we cannot rule-out the influence of sample size on our results. We noticed a trend towards poorer transplant outcomes in patients in second CR, but this trend was not statistically significant. This ambiguity is also in line with the results of a recent study of alloHSCT outcomes in patients with AML with mutated NPM1 which also found worse outcomes in patients in second CR compared with those in the first; however, it did not evaluate pre-transplant MRD level (52).

It is also important to mention the role of the intensity of pre-transplant conditioning regimen in alloHSCT outcomes - especially since, unlike other potential pre-transplant factors (donor type and gender, etc.), we are able to influence this. In our study group, we did not find a statistically significant difference between patients transplanted after MAC and those after RIC. This is supported by the results of several other published studies, where alloHSCT outcomes in AML in CR were also not influenced by the conditioning regimen, but rather only influenced by pretransplant MRD positivity (29-32). In general, however, the published data suggests that reduced-intensity pre-transplant conditioning is associated with a higher risk of posttransplant AML relapse when compared to a MIC; this includes several studies which also evaluated pre-transplant MRD (35, 53-55). In our study group, other potentially prognostic factors (donor type and gender, graft type, donor CMV status) did not significantly influence alloHSCT outcomes, with the exception of age over 63 years, where the 3 -year EFS and OS were $38 \%$. However, this last result was impacted by higher TRM (38\%) among these older patients.

From a practical standpoint, our sample includes a group of patients with low MRD whose 3-year OS was $75 \%$, especially due to low incidence of relapse (only 6\%). Similar results may be found in other published studies - pretransplant MRD-negative patients were reported across several studies to have 3-year OS of $62-77 \%$ and relapse incidence rates of $0-21 \%(29-31,34)$. Thus, this patient group has an overall low risk of AML relapse, leaving TRM, morbidity and quality of life as key factors for alloHSCT outcome. Therefore, for these patients we can preferentially choose an RIC regimen to reduce transplant toxicity. We can also use more potent GVHD prophylaxis and slower tapering of immunosuppression to reduce the risk of GVHD, which is the principal cause of morbidity and mortality after alloHSCT. However, such approaches should be verified in further research. A bolder question is whether alloHSCT is necessary at all in the treatment of these patients, with regard to some recently published data (42).

On the other hand, our study group also included the high pre-transplant MRD group, whose prognosis was notably worse. In our study, these patients had a 3-year OS of $40 \%$ and a relapse incidence rate of $48 \%$. Similar results are again found in other published studies, where 3-year OS in pretransplant MRD-positive patients were in the range of 18$47 \%$ and relapse incidence rates were $41-70 \%(29-31,34)$. The outcomes for pre-transplant MRD-positive patients are thus worse than for MRD-negative patients at a statistically significant level. MRD positivity has been shown to be an independent negative prognostic factor for AML treatment outcomes of patients treated with only standard chemotherapy in a fairly large body of research $(15-18,20$ $22,26,42,56)$. Therefore, MRD positivity can be considered an independent negative biological characteristic of the disease in the context of standard chemotherapy of AML. Outcomes in MRD-positive patients where chemotherapy treatment is used alone are highly unfavorable. One of the most recent larger published studies on patients with AML with NPM1 mutation gives 3-year OS of only $24 \%$ for patients with persistent positive NPM1 expression after two treatment cycles (42). Combining our results with other published research, pre-transplant MRD-positive patients with AML in CR achieve 3-year OS of around 40\%; we can thus infer that alloHSCT partially improves their unfavorable prognosis compared to chemotherapy alone. At present, it remains unclear whether the outcome of alloHSCT in patients with MRD-positive AML in CR can be improved. In this potentially high-risk group, several ways to influence alloHSCT outcomes can be contemplated. In cases where MRD positivity persists during chemotherapy, there is the possibility of attempting to achieve MRD negativity through further cytostatic treatment; however, based on published data, the efficacy of this approach is debatable $(26,57)$. Another option is to try and influence MRD positivity with a more intensive pre-alloHSCT regimen, but based on our results as well as the results of several other published studies, this approach also does not guarantee an improvement in transplant outcomes (21, 35, 53-55). Furthermore, more intensive pre-transplant conditioning can increase the risk of TRM; this may offset any potential decrease in the risk of relapse, so that OS among alloHSCT patients with an MAC regimen might not change significantly (58). Other options for influencing alloHSCT outcomes in patients with MRD-positive AML in CR include an attempt to increase the graft versus leukemia effect by early post-transplant tapering of immunosuppression or by a pre-emptive infusion of donor lymphocytes $(59,60)$. In recent years, it has also become attractive to combine the abovementioned graft versus leukemia potentiation with other treatments, either standard cytostatics or newer targeted therapy (hypomethylating agents, antibodies, tyrosine kinase inhibitors, etc.). Certain recent publications have shown azacytidine and deoxyazacytidine to be effective in posttransplant pre-emptive relapse treatment (61-63). However, 
the studies published so far are not large and no standard post-transplant pre-emptive treatment is currently being generally recommended for AML.

The results of our study show that any potential posttransplant therapeutic intervention should be initiated in a timely manner, as our patients with AML in CR and high MRD levels experienced relapse after a fairly short median period of 4 months. In general, we can say that the inferior alloHSCT outcomes found in patients with MRD-positive AML in CR open the field for further research that would identify additional negative prognostic factors for this patient group, as well as for prospective intervention studies that would further investigate the benefits of the discussed therapeutic options with regard to improving the prognosis of these patients.

\section{Conflicts of Interest}

The Authors declare no conflict of interest in regard to this study.

\section{Acknowledgements}

The Authors thank the physicians and nurses of the HCT teams and staff of the Molecular-Genetics Laboratory of the Department of Hematology and Oncology of the Faculty Hospital Plzen.

This study was supported by Ministry of Health grant 15-30661A and by the National Sustainability Program I (NPU I) Nr. LO1503 provided by the Ministry of Education Youth and Sports of the Czech Republic.

\section{References}

1 Slovak ML, Kopecky KJ, Cassileth PA, Harrington DH, Theil KS, Mohamed A, Paietta E, Willman CL, Head DR, Rowe JM, Forman SJ and Appelbaum FR: Karyotypic analysis predicts outcome of preremission and postremission therapy in adult acute myeloid leukemia: a Southwest Oncology Group/Eastern Cooperative Oncology Group Study. Blood 96: 4075-4083, 2000.

2 Byrd JC, Mrózek K, Dodge RK, Carroll AJ, Edwards CG, Arthur DC, Pettenati MJ, Patil SR, Rao KW, Watson MS, Koduru PRK, Moore JO, Stone RM, Mayer RJ, Feldman EJ, Davey FR, Schiffer CA, Larson RA, Bloomfield CD and Cancer and Leukemia Group B (CALGB 8461): Pretreatment cytogenetic abnormalities are predictive of induction success, cumulative incidence of relapse, and overall survival in adult patients with de novo acute myeloid leukemia: results from Cancer and Leukemia Group B (CALGB 8461). Blood 100: 4325-4336, 2002.

3 Döhner H, Estey EH, Amadori S, Appelbaum FR, Büchner T, Burnett AK, Dombret H, Fenaux P, Grimwade D, Larson RA, Lo-Coco F, Naoe T, Niederwieser D, Ossenkoppele GJ, Sanz MA, Sierra J, Tallman MS, Löwenberg B, Bloomfield CD and European LeukemiaNet: Diagnosis and management of acute myeloid leukemia in adults: recommendations from an international expert panel, on behalf of the European LeukemiaNet. Blood 115: 453-474, 2010.
4 Grimwade D, Hills RK, Moorman AV, Walker H, Chatters S, Goldstone AH, Wheatley K, Harrison CJ, Burnett AK and National Cancer Research Institute Adult Leukaemia Working Group: Refinement of cytogenetic classification in acute myeloid leukemia: determination of prognostic significance of rare recurring chromosomal abnormalities among 5876 younger adult patients treated in the United Kingdom Medical Research Council trials. Blood 116: 354-365, 2010.

5 Breems DA, Van Putten WLJ, De Greef GE, Van ZelderenBhola SL, Gerssen-Schoorl KBJ, Mellink CHM, Nieuwint A, Jotterand M, Hagemeijer A, Beverloo HB and Löwenberg B: Monosomal karyotype in acute myeloid leukemia: a better indicator of poor prognosis than a complex karyotype. J Clin Oncol Off J Am Soc Clin Oncol 26: 4791-4797, 2008.

6 Kanate AS, Pasquini MC, Hari PN and Hamadani M: Allogeneic hematopoietic cell transplant for acute myeloid leukemia: Current state in 2013 and future directions. World J Stem Cells 6: 69-81, 2014.

7 Horan JT, Logan BR, Agovi-Johnson M-A, Lazarus HM, Bacigalupo AA, Ballen KK, Bredeson CN, Carabasi MH, Gupta V, Hale GA, Khoury HJ, Juckett MB, Litzow MR, Martino R, McCarthy PL, Smith FO, Rizzo JD and Pasquini MC: Reducing the risk for transplantation-related mortality after allogeneic hematopoietic cell transplantation: how much progress has been made? J Clin Oncol Off J Am Soc Clin Oncol 29: 805-813, 2011.

8 Cornelissen JJ, van Putten WLJ, Verdonck LF, Theobald M, Jacky E, Daenen SMG, van Marwijk Kooy M, Wijermans P, Schouten H, Huijgens PC, van der Lelie H, Fey M, Ferrant A, Maertens J, Gratwohl A and Lowenberg B: Results of a HOVON/SAKK donor versus no-donor analysis of myeloablative HLA-identical sibling stem cell transplantation in first remission acute myeloid leukemia in young and middleaged adults: benefits for whom? Blood 109: 3658-3666, 2007.

9 Zittoun RA, Mandelli F, Willemze R, de Witte T, Labar B, Resegotti L, Leoni F, Damasio E, Visani G and Papa G: Autologous or allogeneic bone marrow transplantation compared with intensive chemotherapy in acute myelogenous leukemia. European Organization for Research and Treatment of Cancer (EORTC) and the Gruppo Italiano Malattie Ematologiche Maligne dell'Adulto (GIMEMA) Leukemia Cooperative Groups. N Engl J Med 332: 217-223, 1995.

10 Harousseau JL, Cahn JY, Pignon B, Witz F, Milpied N, Delain M, Lioure B, Lamy T, Desablens B, Guilhot F, Caillot D, Abgrall JF, Francois S, Briere J, Guyotat D, Casassus P, Audhuy B, Tellier Z, Hurteloup P and Herve P: Comparison of autologous bone marrow transplantation and intensive chemotherapy as post-remission therapy in adult acute myeloid leukemia. The Groupe Ouest Est Leucémies Aiguës Myéloblastiques (GOELAM). Blood 90: 2978-2986, 1997.

11 Cassileth PA, Harrington DP, Appelbaum FR, Lazarus HM, Rowe JM, Paietta E, Willman C, Hurd DD, Bennett JM, Blume KG, Head DR and Wiernik PH: Chemotherapy compared with autologous or allogeneic bone marrow transplantation in the management of acute myeloid leukemia in first remission. $\mathrm{N}$ Engl J Med 339: 1649-1656, 1998.

12 Suciu S, Mandelli F, de Witte T, Zittoun R, Gallo E, Labar B, De Rosa G, Belhabri A, Giustolisi R, Delarue R, Liso V, Mirto S, Leone G, Bourhis J-H, Fioritoni G, Jehn U, Amadori S, Fazi $\mathrm{P}$, Hagemeijer A, Willemze R and EORTC and GIMEMA 
Leukemia Groups: Allogeneic compared with autologous stem cell transplantation in the treatment of patients younger than 46 years with acute myeloid leukemia (AML) in first complete remission (CR1): an intention-to-treat analysis of the EORTC/GIMEMAAML-10 trial. Blood 102: 1232-1240, 2003.

13 Schmid C, Labopin M, Nagler A, Niederwieser D, Castagna L, Tabrizi R, Stadler M, Kuball J, Cornelissen J, Vorlicek J, Socié G, Falda M, Vindeløv L, Ljungman P, Jackson G, Kröger N, Rank A, Polge E, Rocha V, Mohty M and Acute Leukaemia Working Party of the European Group for Blood and Marrow Transplantation (EBMT): Treatment, risk factors, and outcome of adults with relapsed AML after reduced intensity conditioning for allogeneic stem cell transplantation. Blood 119: 1599-1606, 2012.

14 Corbacioglu A, Scholl C, Schlenk RF, Eiwen K, Du J, Bullinger L, Fröhling S, Reimer P, Rummel M, Derigs H-G, Nachbaur D, Krauter J, Ganser A, Döhner H and Döhner K: Prognostic impact of minimal residual disease in CBFB-MYH11-positive acute myeloid leukemia. J Clin Oncol Off J Am Soc Clin Oncol 28: 3724-3729, 2010.

15 Yin JAL, O'Brien MA, Hills RK, Daly SB, Wheatley K and Burnett AK: Minimal residual disease monitoring by quantitative RT-PCR in core binding factor AML allows risk stratification and predicts relapse: results of the United Kingdom MRC AML15 trial. Blood 120: 2826-2835, 2012.

16 Gorello P, Cazzaniga G, Alberti F, Dell'Oro MG, Gottardi E, Specchia G, Roti G, Rosati R, Martelli MF, Diverio D, Lo Coco F, Biondi A, Saglio G, Mecucci C and Falini B: Quantitative assessment of minimal residual disease in acute myeloid leukemia carrying nucleophosmin (NPM1) gene mutations. Leukemia 20: 1103-1108, 2006.

17 Schnittger S, Kern W, Tschulik C, Weiss T, Dicker F, Falini B, Haferlach $\mathrm{C}$ and Haferlach T: Minimal residual disease levels assessed by NPM1 mutation-specific RQ-PCR provide important prognostic information in AML. Blood 114: 22202231, 2009.

18 Krönke J, Schlenk RF, Jensen K-O, Tschürtz F, Corbacioglu A, Gaidzik VI, Paschka P, Onken S, Eiwen K, Habdank M, Späth D, Lübbert M, Wattad M, Kindler T, Salih HR, Held G, Nachbaur D, von Lilienfeld-Toal M, Germing U, Haase D, Mergenthaler H-G, Krauter J, Ganser A, Göhring G, Schlegelberger B, Döhner $\mathrm{H}$ and Döhner K: Monitoring of minimal residual disease in NPM1-mutated acute myeloid leukemia: a study from the German-Austrian acute myeloid leukemia study group. J Clin Oncol Off J Am Soc Clin Oncol 29: 2709-2716, 2011.

19 Shayegi N, Kramer M, Bornhäuser M, Schaich M, Schetelig J, Platzbecker U, Röllig C, Heiderich C, Landt O, Ehninger G, Thiede $\mathrm{C}$ and Study Alliance Leukemia (SAL): The level of residual disease based on mutant NPM1 is an independent prognostic factor for relapse and survival in AML. Blood 122: 83-92, 2013.

20 Cilloni D, Messa F, Arruga F, Defilippi I, Gottardi E, Fava M, Carturan S, Catalano R, Bracco E, Messa E, Nicoli P, Diverio D, Sanz MA, Martinelli G, Lo-Coco F and Saglio G: Early prediction of treatment outcome in acute myeloid leukemia by measurement of WT1 transcript levels in peripheral blood samples collected after chemotherapy. Haematologica 93: 921-924, 2008.

21 Cilloni D, Renneville A, Hermitte F, Hills RK, Daly S, Jovanovic JV, Gottardi E, Fava M, Schnittger S, Weiss T, Izzo
B, Nomdedeu J, van der Heijden A, van der Reijden BA, Jansen JH, van der Velden VHJ, Ommen H, Preudhomme C, Saglio G and Grimwade D: Real-time quantitative polymerase chain reaction detection of minimal residual disease by standardized WT1 assay to enhance risk stratification in acute myeloid leukemia: a European LeukemiaNet study. J Clin Oncol Off J Am Soc Clin Oncol 27: 5195-5201, 2009.

22 Najima Y, Ohashi K, Kawamura M, Onozuka Y, Yamaguchi T, Akiyama $\mathrm{H}$ and Sakamaki H: Molecular monitoring of BAALC expression in patients with CD34-positive acute leukemia. Int J Hematol 91: 636-645, 2010.

23 Østergaard M, Olesen LH, Hasle H, Kjeldsen E and Hokland P: WT1 gene expression: an excellent tool for monitoring minimal residual disease in $70 \%$ of acute myeloid leukaemia patients results from a single-centre study. Br J Haematol 125: 590-600, 2004.

24 Kern W, Voskova D, Schoch C, Hiddemann W, Schnittger S and Haferlach T: Determination of relapse risk based on assessment of minimal residual disease during complete remission by multiparameter flow cytometry in unselected patients with acute myeloid leukemia. Blood 104: 3078-3085, 2004.

25 Al-Mawali A, Gillis D and Lewis I: The use of receiver operating characteristic analysis for detection of minimal residual disease using five-color multiparameter flow cytometry in acute myeloid leukemia identifies patients with high risk of relapse. Cytometry B Clin Cytom 76: 91-101, 2009.

26 Buccisano F, Maurillo L, Gattei V, Del Poeta G, Del Principe MI, Cox MC, Panetta P, Consalvo MI, Mazzone C, Neri B, Ottaviani L, Fraboni D, Tamburini A, Lo-Coco F, Amadori S and Venditti A: The kinetics of reduction of minimal residual disease impacts on duration of response and survival of patients with acute myeloid leukemia. Leukemia 20: 17831789, 2006.

27 Fung HC, Stein A, Slovak M 1, O'donnell MR, Snyder DS, Cohen S, Smith D, Krishnan A, Spielberger R, Bhatia R, Bhatia S, Falk P, Molina A, Nademanee A, Parker P, Rodriguez R, Rosenthal J, Sweetman R, Kogut N, Sahebi F, Popplewell L, Vora N, Somlo G, Margolin K, Chow W, Smith E and Forman SJ: A long-term follow-up report on allogeneic stem cell transplantation for patients with primary refractory acute myelogenous leukemia: impact of cytogenetic characteristics on transplantation outcome. Biol Blood Marrow Transplant J Am Soc Blood Marrow Transplant 9: 766-771, 2003.

28 Singhal S, Powles R, Henslee-Downey PJ, Chiang KY, Treleaven J, Godder K, Kulkarni S, van Rhee F, Sirohi B, Pinkerton CR, Meller S and Mehta J: Allogeneic transplantation from HLA-matched sibling or partially HLA-mismatched related donors for primary refractory acute leukemia. Bone Marrow Transplant 29: 291-295, 2002.

29 Grubovikj RM, Alavi A, Koppel A, Territo M and Schiller GJ: Minimal residual disease as a predictive factor for relapse after allogeneic hematopoietic stem cell transplant in adult patients with acute myeloid leukemia in first and second complete remission. Cancers 4: 601-617, 2012.

30 Válková V, Polák J, Marková M, Vítek A, Hájková H, Sálek C, Procházka B, Cetkovský $\mathrm{P}$ and Trněný $\mathrm{M}$ : Minimal residual disease detectable by quantitative assessment of WT1 gene before allogeneic stem cell transplantation in patients in first remission of acute myeloid leukemia has an impact on their future prognosis. Clin Transplant 27: E21-29, 2013. 
31 Walter RB, Buckley SA, Pagel JM, Wood BL, Storer BE, Sandmaier BM, Fang M, Gyurkocza B, Delaney C, Radich JP, Estey EH and Appelbaum FR: Significance of minimal residual disease before myeloablative allogeneic hematopoietic cell transplantation for AML in first and second complete remission. Blood 122: 1813-1821, 2013.

32 Walter RB, Gyurkocza B, Storer BE, Godwin CD, Pagel JM, Buckley SA, Sorror ML, Wood BL, Storb R, Appelbaum FR and Sandmaier BM: Comparison of minimal residual disease as outcome predictor for AML patients in first complete remission undergoing myeloablative or nonmyeloablative allogeneic hematopoietic cell transplantation. Leukemia 29: 137-144, 2015.

33 Bastos-Oreiro M, Perez-Corral A, Martínez-Laperche C, Bento L, Pascual C, Kwon M, Balsalobre P, Muñoz C, Buces E, Serrano D, Gayoso J, Buño I, Anguita J and Diéz-Martín JL: Prognostic impact of minimal residual disease analysis by flow cytometry in patients with acute myeloid leukemia before and after allogeneic hemopoietic stem cell transplantation. Eur J Haematol 93: 239-246, 2014.

34 Anthias C, Dignan FL, Morilla R, Morilla A, Ethell ME, Potter MN and Shaw BE: Pre-transplant MRD predicts outcome following reduced-intensity and myeloablative allogeneic hemopoietic SCT in AML. Bone Marrow Transplant 49: 679683,2014

35 Ustun C, Courville EL, DeFor T, Dolan M, Randall N, Yohe S, Bejanyan N, Warlick E, Brunstein C, Weisdorf DJ and Linden MA: Myeloablative, but not reduced-intensity, conditioning overcomes the negative effect of flow-cytometric evidence of leukemia in acute myeloid leukemia. Biol Blood Marrow Transplant J Am Soc Blood Marrow Transplant 22: 669-675, 2016.

36 Swerdlow S, Campo E, Harris N, Jaffe E, Pileri S, Stein H, Thiele J and Vardiman J: WHO Classification of Tumours of Haematopoietic and Lymphoid Tissues, 2008.

37 Cheson BD, Bennett JM, Kopecky KJ, Büchner T, Willman CL, Estey EH, Schiffer CA, Doehner H, Tallman MS, Lister TA, LoCoco F, Willemze R, Biondi A, Hiddemann W, Larson RA, Löwenberg B, Sanz MA, Head DR, Ohno R, Bloomfield CD, LoCocco F and International Working Group for Diagnosis, Standardization of Response Criteria, Treatment Outcomes, and Reporting Standards for Therapeutic Trials in Acute Myeloid Leukemia: Revised recommendations of the International Working Group for Diagnosis, Standardization of Response Criteria, Treatment Outcomes, and Reporting Standards for Therapeutic Trials in Acute Myeloid Leukemia. J Clin Oncol Off J Am Soc Clin Oncol 21: 4642-4649, 2003.

38 Przepiorka D, Weisdorf D, Martin P, Klingemann HG, Beatty P, Hows J and Thomas ED: 1994 Consensus Conference on Acute GVHD Grading. Bone Marrow Transplant 15: 825-828, 1995.

39 Filipovich AH, Weisdorf D, Pavletic S, Socie G, Wingard JR, Lee SJ, Martin P, Chien J, Przepiorka D, Couriel D, Cowen EW, Dinndorf P, Farrell A, Hartzman R, Henslee-Downey J, Jacobsohn D, McDonald G, Mittleman B, Rizzo JD, Robinson M, Schubert M, Schultz K, Shulman H, Turner M, Vogelsang G and Flowers MED: National Institutes of Health consensus development project on criteria for clinical trials in chronic graft-versus-host disease: I. Diagnosis and staging working group report. Biol Blood Marrow Transplant J Am Soc Blood Marrow Transplant 11: 945-956, 2005.
40 Kristensen T, Møller MB, Friis L, Bergmann OJ and Preiss B: NPM1 mutation is a stable marker for minimal residual disease monitoring in acute myeloid leukaemia patients with increased sensitivity compared to WT1 expression. Eur J Haematol 87: 400-408, 2011.

41 Bacher U, Badbaran A, Fehse B, Zabelina T, Zander AR and Kröger N: Quantitative monitoring of NPM1 mutations provides a valid minimal residual disease parameter following allogeneic stem cell transplantation. Exp Hematol 37: 135-142, 2009.

42 Ivey A, Hills RK, Simpson MA, Jovanovic JV, Gilkes A, Grech A, Patel Y, Bhudia N, Farah H, Mason J, Wall K, Akiki S, Griffiths M, Solomon E, McCaughan F, Linch DC, Gale RE, Vyas P, Freeman SD, Russell N, Burnett AK, Grimwade D and UK National Cancer Research Institute AML Working Group: Assessment of minimal residual disease in standard-risk AML. N Engl J Med 374: 422-433, 2016.

43 Freeman SD, Jovanovic JV and Grimwade D: Development of minimal residual disease-directed therapy in acute myeloid leukemia. Semin Oncol 35: 388-400, 2008.

44 Ossenkoppele GJ, van de Loosdrecht AA and Schuurhuis GJ: Review of the relevance of aberrant antigen expression by flow cytometry in myeloid neoplasms. Br J Haematol 153: 421-436, 2011.

45 Oelschlägel U, Nowak R, Schaub A, Köppel C, Herbst R, Mohr B, Löffler C, Range U, Günther H, Assmann M, Siegert E, Wendt E, Huhn R, Bräutigam E and Ehninger G: Shift of aberrant antigen expression at relapse or at treatment failure in acute leukemia. Cytometry 42: 247-253, 2000.

46 Dvorakova D, Racil Z, Jeziskova I, Palasek I, Protivankova M, Lengerova M, Razga $\mathrm{F}$ and Mayer J: Monitoring of minimal residual disease in acute myeloid leukemia with frequent and rare patient-specific NPM1 mutations. Am J Hematol 85: 926929, 2010.

47 Ottone T, Zaza S, Divona M, Hasan SK, Lavorgna S, Laterza S, Cicconi L, Panetta P, Di Giandomenico J, Cittadini M, Ciardi C, Montefusco E, Franchi A, Annino L, Venditti A, Amadori S and Lo-Coco F: Identification of emerging FLT3 ITD-positive clones during clinical remission and kinetics of disease relapse in acute myeloid leukaemia with mutated nucleophosmin. Br J Haematol 161: 533-540, 2013.

48 Appelbaum FR: Measurement of minimal residual disease before and after myeloablative hematopoietic cell transplantation for acute leukemia. Best Pract Res Clin Haematol 26: 279-284, 2013.

49 Ustun C, Wiseman AC, Defor TE, Yohe S, Linden MA, Oran B, Burke M, Warlick E, Miller JS and Weisdorf D: Achieving stringent $\mathrm{CR}$ is essential before reduced-intensity conditioning allogeneic hematopoietic cell transplantation in AML. Bone Marrow Transplant 48: 1415-1420, 2013.

50 Mrózek K, Marcucci G, Nicolet D, Maharry KS, Becker H, Whitman SP, Metzeler KH, Schwind S, Wu Y-Z, Kohlschmidt J, Pettenati MJ, Heerema NA, Block AW, Patil SR, Baer MR, Kolitz JE, Moore JO, Carroll AJ, Stone RM, Larson RA and Bloomfield CD: Prognostic significance of the European LeukemiaNet standardized system for reporting cytogenetic and molecular alterations in adults with acute myeloid leukemia. J Clin Oncol Off J Am Soc Clin Oncol 30: 4515-4523, 2012.

51 Thiede C, Koch S, Creutzig E, Steudel C, Illmer T, Schaich M and Ehninger G: Prevalence and prognostic impact of NPM1 mutations in 1485 adult patients with acute myeloid leukemia (AML). Blood 107: 4011-4020, 2006. 
52 Bazarbachi A, Labopin M, Kharfan-Dabaja MA, Schwerdtfeger R, Volin L, Bourhis JH, Socié G, Daguindau E, Gedde-Dahl T, Rambaldi A, Karas M, Schlimok G, Blaise D, Chevallier P, Malard F, Schmid C, Esteve J, Nagler A and Mohty M: Allogeneic hematopoietic cell transplantation in acute myeloid leukemia with normal karyotype and isolated nucleophosmin-1 (NPM1) mutation: outcome strongly correlates with disease status. Haematologica 101: e34-37, 2016.

53 Alyea EP, Kim HT, Ho V, Cutler C, Gribben J, DeAngelo DJ, Lee SJ, Windawi S, Ritz J, Stone RM, Antin JH and Soiffer RJ: Comparative outcome of nonmyeloablative and myeloablative allogeneic hematopoietic cell transplantation for patients older than 50 years of age. Blood 105: 1810-1814, 2005.

54 de Lima M, Anagnostopoulos A, Munsell M, Shahjahan M, Ueno N, Ippoliti C, Andersson BS, Gajewski J, Couriel D, Cortes J, Donato M, Neumann J, Champlin R and Giralt S: Non-ablative versus reduced-intensity conditioning regimens in the treatment of acute myeloid leukemia and high-risk myelodysplastic syndrome: dose is relevant for long-term disease control after allogeneic hematopoietic stem cell transplantation. Blood 104: 865-872, 2004.

55 Martino R, de Wreede L, Fiocco M, van Biezen A, von dem Borne PA, Hamladji R-M, Volin L, Bornhäuser M, Robin M, Rocha V, de Witte T, Kröger N, Mohty M and Acute Leukemia Working Party the subcommittee for Myelodysplastic Syndromes of the Chronic Malignancies Working Party of the European group for Blood Marrow Transplantation Group (EBMT): Comparison of conditioning regimens of various intensities for allogeneic hematopoietic SCT using HLA-identical sibling donors in AML and MDS with <10\% BM blasts: a report from EBMT. Bone Marrow Transplant 48: 761-770, 2013.

56 Cilloni D, Gottardi E, De Micheli D, Serra A, Volpe G, Messa F, Rege-Cambrin G, Guerrasio A, Divona M, Lo Coco F and Saglio G: Quantitative assessment of WT1 expression by real time quantitative PCR may be a useful tool for monitoring minimal residual disease in acute leukemia patients. Leukemia 16: 2115-2121, 2002.

57 Maurillo L, Buccisano F, Del Principe MI, Del Poeta G, Spagnoli A, Panetta P, Ammatuna E, Neri B, Ottaviani L, Sarlo C, Venditti D, Quaresima M, Cerretti R, Rizzo M, de Fabritiis P, Lo Coco F, Arcese W, Amadori S and Venditti A: Toward optimization of postremission therapy for residual disease-positive patients with acute myeloid leukemia. J Clin Oncol 26: 4944-4951, 2008.

58 Aoudjhane M, Labopin M, Gorin NC, Shimoni A, Ruutu T, Kolb HJ, Frassoni F, Boiron JM, Yin JL, Finke J, Shouten H, Blaise D, Falda M, Fauser AA, Esteve J, Polge E, Slavin S, Niederwieser D, Nagler A, Rocha V and Acute Leukemia Working Party (ALWP) of the European group for Blood and Marrow Transplantation (EBMT): Comparative outcome of reduced intensity and myeloablative conditioning regimen in HLA identical sibling allogeneic haematopoietic stem cell transplantation for patients older than 50 years of age with acute myeloblastic leukaemia: a retrospective survey from the Acute Leukemia Working Party (ALWP) of the European group for Blood and Marrow Transplantation (EBMT). Leukemia 19: 2304-2312, 2005.

59 Rettinger E, Willasch AM, Kreyenberg H, Borkhardt A, Holter W, Kremens B, Strahm B, Woessmann W, Mauz-Koerholz C, Gruhn B, Burdach S, Albert MH, Schlegel P-G, Klingebiel T and Bader P: Preemptive immunotherapy in childhood acute myeloid leukemia for patients showing evidence of mixed chimerism after allogeneic stem cell transplantation. Blood 118: 5681-5688, 2011.

60 Yan C-H, Liu D-H, Liu K-Y, Xu L-P, Liu Y-R, Chen H, Han W, Wang Y, Qin Y-Z and Huang X-J: Risk stratification-directed donor lymphocyte infusion could reduce relapse of standard-risk acute leukemia patients after allogeneic hematopoietic stem cell transplantation. Blood 119: 3256-3262, 2012.

61 Platzbecker U, Wermke M, Radke J, Oelschlaegel U, Seltmann F, Kiani A, Klut I-M, Knoth H, Röllig C, Schetelig J, Mohr B, Graehlert $\mathrm{X}$, Ehninger $\mathrm{G}$, Bornhäuser $\mathrm{M}$ and Thiede $\mathrm{C}$ : Azacitidine for treatment of imminent relapse in MDS or AML patients after allogeneic HSCT: results of the RELAZA trial. Leukemia 26: 381-389, 2012.

62 Schroeder T, Rachlis E, Bug G, Stelljes M, Klein S, Steckel NK, Wolf D, Ringhoffer M, Czibere A, Nachtkamp K, Dienst A, Kondakci M, Stadler M, Platzbecker U, Uharek L, Luft T, Fenk R, Germing U, Bornhäuser M, Kröger N, Beelen DW, Haas R and Kobbe G: Treatment of acute myeloid leukemia or myelodysplastic syndrome relapse after allogeneic stem cell transplantation with azacitidine and donor lymphocyte infusions-a retrospective multicenter analysis from the German Cooperative Transplant Study Group. Biol Blood Marrow Transplant J Am Soc Blood Marrow Transplant 21: 653-660, 2015.

63 Pusic I, Choi J, Fiala MA, Gao F, Holt M, Cashen AF, Vij R, Abboud CN, Stockerl-Goldstein KE, Jacoby MA, Uy GL, Westervelt $\mathrm{P}$ and DiPersio JF: Maintenance Therapy with Decitabine after Allogeneic Stem Cell Transplantation for Acute Myelogenous Leukemia and Myelodysplastic Syndrome. Biol Blood Marrow Transplant J Am Soc Blood Marrow Transplant 21: 1761-1769, 2015.
Received August 22, 2016

Revised September 16, 2016

Accepted September 20, 2016 